\title{
Development of a quantitative pharmacodynamic assay for apoptosis in fixed tumor tissue and its application in distinguishing cytotoxic drug-induced DNA double strand breaks from DNA double strand breaks associated with apoptosis
}

\author{
Angie B. Dull ${ }^{1}$, Deborah Wilsker ${ }^{1}$, Melinda Hollingshead ${ }^{2}$, Christina Mazcko $^{3}$, \\ Christina M. Annunziata ${ }^{4}$, Amy K. LeBlanc ${ }^{3}$, James H. Doroshow ${ }^{5}$, Robert J. Kinders ${ }^{1}$ \\ and Ralph E. Parchment ${ }^{1}$ \\ ${ }^{1}$ Clinical Pharmacodynamic Biomarkers Program, Applied/Developmental Research Directorate, Leidos Biomedical Research, \\ Frederick National Laboratory for Cancer Research, Frederick, Maryland, USA \\ ${ }^{2}$ Biological Testing Branch, National Cancer Institute-Frederick, Frederick, Maryland, USA \\ ${ }^{3}$ Comparative Oncology Program, National Cancer Institute, Bethesda, Maryland, USA \\ ${ }^{4}$ Women's Malignancies Branch, National Cancer Institute, Bethesda, Maryland, USA \\ ${ }^{5}$ Division of Cancer Treatment and Diagnosis and Center for Cancer Research, National Cancer Institute, Bethesda, Maryland, \\ USA \\ Correspondence to: Deborah Wilsker, email: deborah.wilsker@nih.gov \\ Ralph E. Parchment, email: parchmentr@mail.nih.gov \\ Keywords: immunofluorescence; pharmacodynamic assay; DNA double strand breaks; multiplex; apoptosis \\ Received: January 19, $2018 \quad$ Accepted: March 06, $2018 \quad$ Published: March 30, 2018 \\ Copyright: Dull et al. This is an open-access article distributed under the terms of the Creative Commons Attribution License 3.0 \\ (CC BY 3.0), which permits unrestricted use, distribution, and reproduction in any medium, provided the original author and source \\ are credited.
}

\section{ABSTRACT}

DNA double strand breaks (DSBs) induced by cancer therapeutic agents can lead to DNA damage repair or persistent DNA damage, which can induce apoptotic cell death; however, apoptosis also induces DSBs independent of genotoxic insult. YH2AX is an established biomarker for DSBs but cannot distinguish between these mechanisms. Activated cleaved caspase-3 (CC3) promotes apoptosis by enhancing nuclear condensation, DNA fragmentation, and plasma membrane blebbing. Here, we describe an immunofluorescence assay that distinguishes between apoptosis and drug-induced DSBs by measuring coexpression of yH2AX and membrane blebbingassociated $\mathrm{CC} 3$ to indicate apoptosis, and YH2AX in the absence of CC3 blebbing to indicate drug-induced DNA damage. These markers were examined in xenograft models following treatment with topotecan, cisplatin, or birinapant. A topotecan regimen conferring tumor regression induced tumor cell DSBs resulting from both apoptosis and direct DNA damage. In contrast, a cisplatin regimen yielding tumor growth delay, but not regression, resulted in tumor cell DSBs due solely to direct DNA damage. MDA-MB-231 xenografts exposed to birinapant, which promotes apoptosis but does not directly induce DSBs, exhibited dose-dependent increases in colocalized YH2AX/CC3 blebbing in tumor cells. Clinical feasibility was established using formalinfixed, paraffin-embedded biopsies from a canine cancer clinical trial; YH2AX/CC3 colocalization analysis revealed apoptosis induction by two novel indenoisoquinoline topoisomerase I inhibitors, which was consistent with pathologist-assessed apoptosis and reduction of tumor volume. This assay is ready for use in clinical trials to elucidate the mechanism of action of investigational agents and combination regimens intended to inflict DNA damage, apoptotic cell death, or both. 


\section{INTRODUCTION}

The histone protein $\mathrm{H} 2 \mathrm{AX}$ is phosphorylated on serine 139 to form $\gamma \mathrm{H} 2 \mathrm{AX}$ at sites of DNA doublestrand breaks (DSBs), and this phosphorylation is required for the recruitment of DNA repair factors after DNA damage. Our lab and others have demonstrated the appearance of $\gamma \mathrm{H} 2 \mathrm{AX}$ after treatment with genotoxic agents by immunofluorescence assay using formalinfixed, paraffin-embedded tumor tissue [1-3]. The $\gamma \mathrm{H} 2 \mathrm{AX}$ immunofluorescence assay (IFA) we developed for analysis of clinical specimens has been widely used across numerous NCI-sponsored clinical trials to reliably detect DSBs in tumor cells examined in clinical specimens. However, while the function of $\gamma \mathrm{H} 2 \mathrm{AX}$ was originally believed to be associated primarily with DNA repair, its role as a marker in DNA ladder formation during apoptosis has been well-established $[4,5]$. Therefore, the observed $\gamma \mathrm{H} 2 \mathrm{AX}$ signal in clinical specimens could be indicative of apoptosis rather than DNA repair. We sought to resolve this ambiguity by developing an immunofluorescence microscopy assay to identify and enumerate $\gamma \mathrm{H} 2 \mathrm{AX}$ positive cells undergoing apoptosis.

One hallmark of apoptosis is the cleavage-induced activation of caspase- 3 , an executioner caspase that promotes cell death by increasing the proteolysis of a variety of protein substrates. In the intrinsic apoptotic pathway, cytochrome $c$-mediated apoptosome formation induces procaspase- 9 cleavage; activated caspase- 9 then catalyzes the proteolytic processing of caspase-3, forming active cleaved caspase-3. Cleaved caspase-3 (CC3) is used as a marker of apoptosis in sandwich ELISA [6] and immunohistochemical analyses, but the detection of substantial levels of this activated caspase in many nonapoptotic cells [7-9] has confounded the use of $\mathrm{CC} 3$ alone as a specific, quantitative marker of apoptosis. Though the functional role of $\mathrm{CC} 3$ in non-apoptotic cells has not been fully explored, the presence of this protein may be due to its well-documented involvement in cell differentiation [10-16]. Thus, although CC3 is an integral executioner caspase essential for apoptosis, the alternate functions of this protein in non-apoptotic cells render it non-specific as a molecular biomarker of apoptosis.

However, in our efforts to resolve interpretation of the $\gamma \mathrm{H} 2 \mathrm{AX}$ immunofluorescence signal in tumor tissue, we observed formation of CC3 aggregates, or puncta, in cells undergoing apoptosis. Caspase-mediated cleavage of type I keratins during apoptosis is known to lead to formation of such CC3-containing puncta independent of $\gamma \mathrm{H} 2 \mathrm{AX}[4,17,18]$, and we found that these $\mathrm{CC} 3$ puncta were associated with the membrane blebbing that is characteristic of apoptotic cells (Supplementary Figure 1). By developing a microscopy method to enumerate cells containing both $\gamma \mathrm{H} 2 \mathrm{AX}$ and these blebbing-associated $\mathrm{CC} 3$ structures, we were able to quantitate apoptotic tumor cells harboring DNA fragmentation. The use of two independent biomarkers, including one that represents both a biochemical and morphological feature of apoptosis, results in an immunofluorescence assay with very high specificity and utility for assessing apoptosis in fixed tissue specimens on the preferred, microscopy platform for $\gamma \mathrm{H} 2 \mathrm{AX}$ evaluation. This method accomplishes two primary goals: first, to define the mechanism of action of novel cancer agents in clinical specimens in which a $\gamma \mathrm{H} 2 \mathrm{AX}$ response has been observed and, second, to report quantitative measurements of apoptosis in fixed tumor tissue.

Here, we present the development and validation of this high-specificity IFA for detection and enumeration of apoptotic cells in tumor tissue. We showed that using membrane blebbing-associated $\mathrm{CC} 3$ instead of total CC3 intensity to enumerate $\mathrm{CC} 3$-positive cells ["CC3(bleb)" IFA] substantially reduces background signal in tumor tissue from untreated canine patients. We applied this $\mathrm{CC} 3$ (bleb) assay together with quantitation of nuclear $\gamma \mathrm{H} 2 \mathrm{AX}$ to distinguish apoptotic from non-apoptotic $\gamma \mathrm{H} 2 \mathrm{AX}$-positive cell populations within tumors from xenograft models treated with the genotoxic agents cisplatin and topotecan in comparison to the pro-apoptotic agent birinapant. Finally, we demonstrated clinical readiness of this assay through its application to patients in a canine lymphoma clinical trial of investigational indenoisoquinoline topoisomerase I inhibitors. These results demonstrate the utility of our assay in dissecting the dynamics of DNA damage response and apoptosis in tumor tissue following treatment with different classes of anticancer therapeutics.

\section{RESULTS}

\section{Identification and enumeration of cleaved caspase- 3 blebbing-positive cells in tumor tissue}

During apoptosis, caspase-mediated cleavage of type I keratins, such as $\mathrm{K} 18$, leads to the formation of large cytoplasmic inclusions, or puncta, containing keratins and CC3 $[17,18]$. This process, together with other cytoskeletal changes, results in the characteristic membrane blebbing observed in apoptotic cells [19]. During our examination of tumor tissue from xenograft models and canine lymphoma biopsy specimens, we found that cells positive for $\mathrm{CC} 3$ puncta also exhibited membrane blebbing, with the latter visualized by immunofluorescence staining of the plasma membrane marker $\mathrm{Na}^{+} / \mathrm{K}^{+}$-ATPase (Supplementary Figure 1). We henceforth refer to cells containing $\mathrm{CC} 3$ puncta as $\mathrm{CC} 3(\mathrm{bleb})^{+}$cells, and we used a combination of ring-based nuclear border dilation and spot algorithms to identify and enumerate $\mathrm{CC} 3(\mathrm{bleb})^{+}$cells in formalin-fixed, paraffinembedded (FFPE) tumor tissue (Figure 1).

To examine whether our assay for $\mathrm{CC} 3(\mathrm{bleb})^{+}$cells provided a more accurate measure of apoptosis relative to 
quantitation of total cytoplasmic CC3, we assessed lymph node biopsy specimens from three canine patients with lymphoma who were enrolled in an ongoing clinical study of the investigational topoisomerase 1 inhibitors LMP400 (indotecan), LMP776 (indimitecan), and LMP744 (Figure 2). Measurements of diffuse cytoplasmic CC3 were highly variable and in some cases reported a signal in patients in which no apoptotic cells could be confirmed by a pathologist's assessment of hematoxylin and eosin ( $\mathrm{H} \& \mathrm{E}$ )-stained slides (Figure 2A and 2B). In contrast, the CC3(bleb) assay accurately captured the pathologistidentified differences in apoptotic frequency between preand post-treatment samples.

Analysis of specimens from patient 1, treated with LMP744, illustrates these differences (Figure 2A). Cytoplasmic CC3 intensity quantitation indicates that $60 \%$ of cells in the pre-dose sample were positive for cytoplasmic CC3, that the percentage of cytoplasmic $\mathrm{CC}^{+}$cells decreased significantly (to approximately $20 \% ; P<0.001) 2$ hours after administration of the first dose, and that the percentages of cytoplasmic $\mathrm{CC}^{+}$cells collected 6 hours post-dose 1 and 24 hours post-dose 5 were not significantly changed from before treatment (Figure 2A). In contrast, CC3(bleb) assay analysis yielded a mean of only $0.3 \% \mathrm{CC} 3$ (bleb) ${ }^{+}$cells in the predose sample, and very small but statistically significant increases in the percentage of CC3(bleb) ${ }^{+}$cells at 2 and 6 hours post-dose 1 and 24 hours post-dose 5 (to $0.8 \%$, $3.3 \%$, and $3.3 \%$, respectively; $P<0.05$ ). These CC3(bleb) assay results reflect the absence of an appreciable number of apoptotic cells observed in the $\mathrm{H} \& \mathrm{E}$ images of these specimens (Figure 2B). Discrepancies between the cytoplasmic $\mathrm{CC} 3$ and $\mathrm{CC} 3$ (bleb) assay results were also observed in specimens collected from patient 2, treated with LMP400 (Figure 2C); cytoplasmic CC3 measurements indicated that the percentage of cytoplasmic $\mathrm{CC}^{+}$cells significantly decreased from 2 hours to 6 hours post-dose 1 (31.6\% to $17.1 \%$, respectively; $P<0.01)$. In contrast, the $\mathrm{CC} 3$ (bleb) assay results indicated a statistically significant increase in CC3(bleb) ${ }^{+}$cells over this same time frame (from $12.3 \%$ to $17.9 \% ; P<0.05$ ), consistent with the increase in apoptotic cells that can be observed in $\mathrm{H}$ \& $\mathrm{E}$ images for the 2- and 6-hour post-dose 1 specimens (Figure 2D). This increase in apoptotic cells at 6 hours post-dose 1 is also consistent with enhanced numbers of "starry sky" tumor-associated macrophages (Figure 2D), which are known to associate with apoptotic cells within some lymphoma tumors [20].

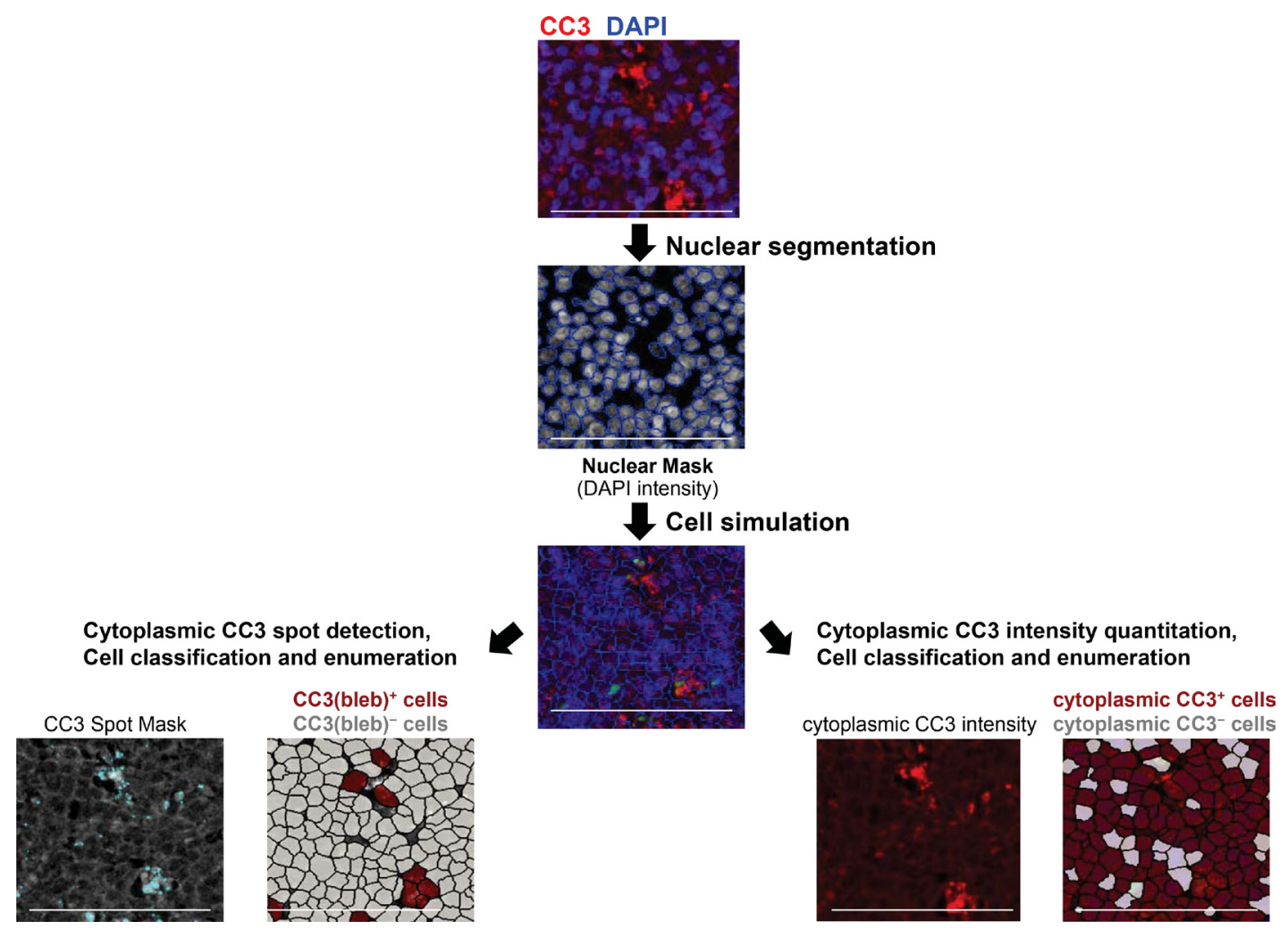

Figure 1: Workflow for enumeration of cleaved caspase-3 bleb-positive $\left[\mathrm{CC} 3(\mathrm{bleb})^{+}\right]$cells in FFPE canine tumor tissue. Images of tissue stained with DAPI and anti-cleaved caspase-3 antibody were first subjected to nuclear segmentation based on DAPI signal and nuclear size. Cytoplasmic areas were then simulated using a ring-based algorithm, defining the cytoplasm through a set dilation from the nuclear border (1-5 $\mu \mathrm{m}$, established automatedly on a specimen-by-specimen basis). CC3 puncta were defined using a spot algorithm (left), with a spot size range of $0.2-5 \mu \mathrm{m}^{2}$, and cells were classified as CC3(bleb) ${ }^{+}$if they contained $\geq 2 \mathrm{CC} 3$ puncta per cell. For comparison, cells were classified based on total cytoplasmic CC3 intensity (right). Scale bar represents $100 \mu \mathrm{m}$. 
For patient 3, treated with LMP776, the relative changes in apoptotic frequency were similar when quantitated by cytoplasmic CC3 intensity or CC3 blebbing (Figure 2E and Supplementary Figure 2), but in none of the cases examined did the cytoplasmic CC3 intensity measurements outperform the CC3(bleb) assay in terms of corresponding with the pathologist's assessment of apoptotic frequency. The $\mathrm{CC} 3$ (bleb) assay also improved the precision of $\mathrm{CC} 3$ positivity measurements in that, for all three patients, variations in the $\mathrm{CC} 3$ (bleb) signal (i.e., standard deviations provided in Figure 2) were smaller than those for total cytoplasmic CC3 intensity at all of the post-treatment time points examined. These data indicate that quantitation of cytoplasmic CC3 intensity is not a suitable approach for incorporation into an assay developed to measure apoptosis and that measurement of
CC3 blebbing offers improved specificity for detection of apoptotic cells.

\section{Colocalization of $\gamma \mathrm{H} 2 \mathrm{AX}$ with $\mathrm{CC} 3$ blebbing distinguishes apoptosis-associated versus DNA damage-induced double-strand breaks}

To evaluate whether the strong $\gamma \mathrm{H} 2 \mathrm{AX}$ signal measured in some of our clinical specimens reflected druginduced DNA DSBs or apoptosis, we explored the utility of combining $\mathrm{CC} 3$ blebbing analysis with our previously validated IFA for $\gamma \mathrm{H} 2 \mathrm{AX}[1,21]$. Measuring coexpression of these markers within multiple, individual cells (Figure 3) allowed us to interpret whether $\gamma \mathrm{H} 2 \mathrm{AX}$ expression in a given cell is indicative of DNA damage due to genotoxic insult, or the induction of apoptosis and the associated
A

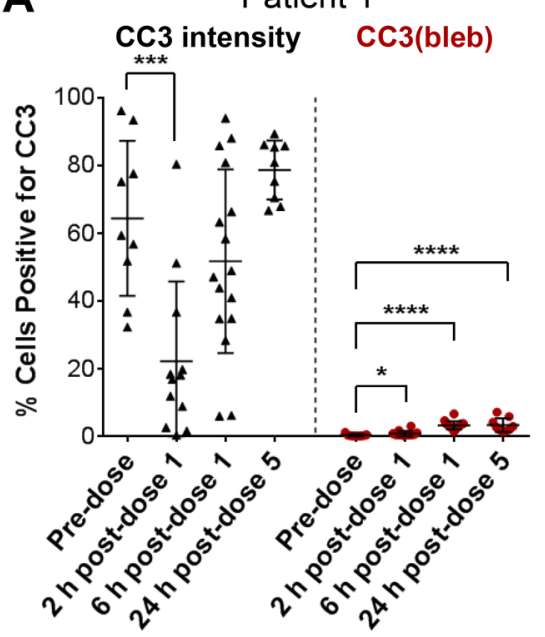

C

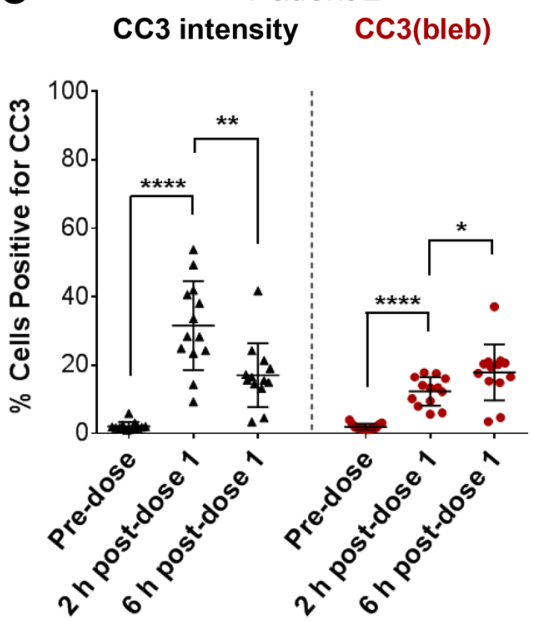

E

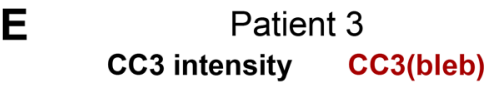

B
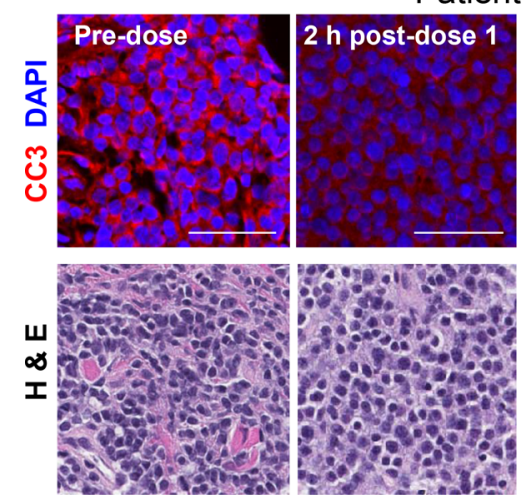

Patient 1
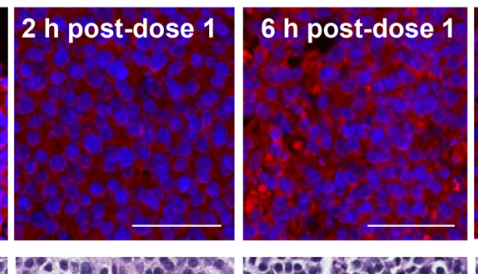
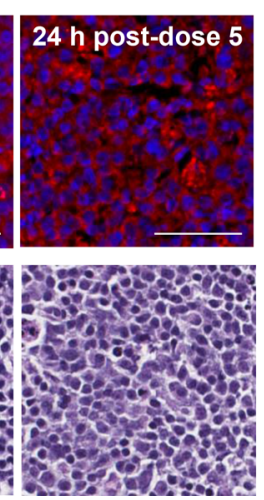

D
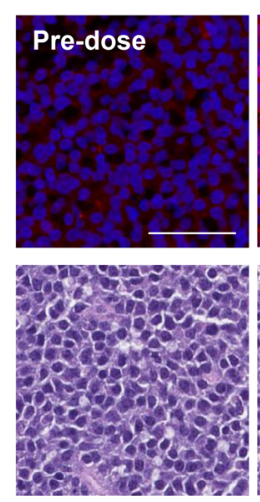

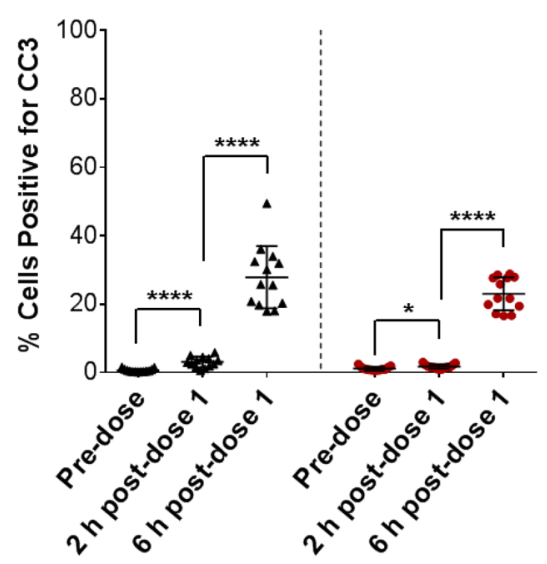

Patient 2

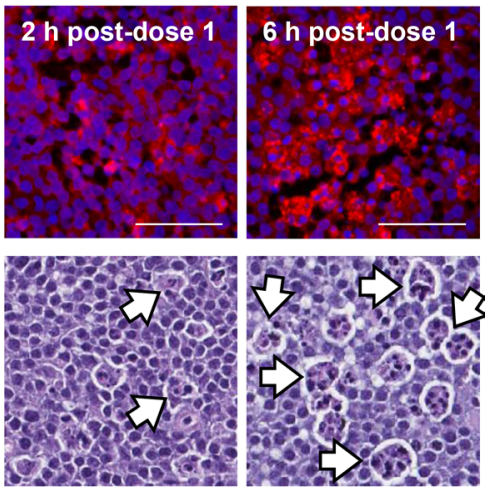

Figure 2: A CC3 blebbing mask improves the accuracy and precision of CC3 IFA-based apoptotic cell enumeration in FFPE tumor biopsy samples from canine lymphoma patients. Needle biopsies were obtained 2 and $6 \mathrm{~h}$ post-dose 1 or $24 \mathrm{~h}$ postdose 5 of QD $\times 5$ treatment with the investigational indenoisoquinoline topoisomerase I inhibitors LMP744 (Patient 1), LMP400 (Patient 2), or LMP776 (Patient 3). (A, C, and E) Quantitation of cells positive for total cytoplasmic CC3 intensity (left, black) and CC3 blebbing (right, red) in tumor tissue collected at baseline and following treatment with investigational agents. Data are shown for 3 individual patients; each data point represents one image field, and lines indicate means \pm standard deviations. Asterisks indicate statistically significant differences for comparisons with the pre-dose group (A) or for pre-dose vs. $2 \mathrm{~h}$ post-dose and $2 \mathrm{~h}$ vs. $6 \mathrm{~h}$ post-dose groups $\left(\mathrm{C}\right.$ and $\mathrm{E}$; ${ }^{*} P<0.05$, ${ }^{* *} P<0.01,{ }^{* * *} P<0.001,{ }^{* * * *} P<0.0001$ ). (B and D) Representative CC3/DAPI IFA and H \& E images for patients 1 and 2 . Scale bars represent $50 \mu \mathrm{m}$. White arrows indicate representative, pathologist-annotated "starry-sky" tumor-associated macrophages. IFA and H \& E images from Patient 3 are presented in Supplementary Figure 2. 
genome-wide chromosomal DNA fragmentation [22]. Cellular colocalization of $\gamma \mathrm{H} 2 \mathrm{AX}$ and CC3(bleb) signals provides a highly specific marker of apoptosis, indicating apoptotic cells that have undergone DNA fragmentation.

We first applied the $\gamma \mathrm{H} 2 \mathrm{AX} / \mathrm{CC} 3$ (bleb) assay to examine the induction of DNA damage response and apoptosis pathways following treatment with the genotoxic DNA topoisomerase I inhibitor topotecan in the A375 melanoma xenograft model (Figure 4A). Administration of 1.5 or $4.7 \mathrm{mg} / \mathrm{kg}$ topotecan has been shown to induce robust tumor $\gamma \mathrm{H} 2 \mathrm{AX}$ expression and dose-dependent tumor regression [1]. Application of the $\gamma \mathrm{H} 2 \mathrm{AX} / \mathrm{CC} 3(\mathrm{bleb})$ assay to xenograft tumor samples collected 4 hours after topotecan treatment confirmed this dose-dependent increase in $\gamma \mathrm{H} 2 \mathrm{AX}$ (Figure 4B). At the two highest dose levels of topotecan, which were associated with antitumor efficacy, approximately $20 \%$ of the $\gamma \mathrm{H} 2 \mathrm{AX}^{+}$cells were also positive for CC3 blebbing at 4 hours post administration, indicating that an appreciable portion of the total $\gamma \mathrm{H} 2 \mathrm{AX}$ signal is associated with apoptotic nuclei undergoing DNA fragmentation. At the lowest dose level and for the vehicle-treated group, the total $\gamma \mathrm{H} 2 \mathrm{AX}$ signals were lower, and CC3 blebbing was observed in only $10 \%$ of the $\gamma \mathrm{H} 2 \mathrm{AX}^{+}$cells (Figure 4B). The significant increase in the percentage of $\gamma \mathrm{H}_{2} \mathrm{AX}^{+} /$ $\mathrm{CC} 3(\mathrm{bleb})^{+}$cells for the 1.5 and $4.7 \mathrm{mg} / \mathrm{kg}$ topotecan

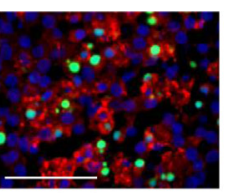

DAPI CC3 YH2AX

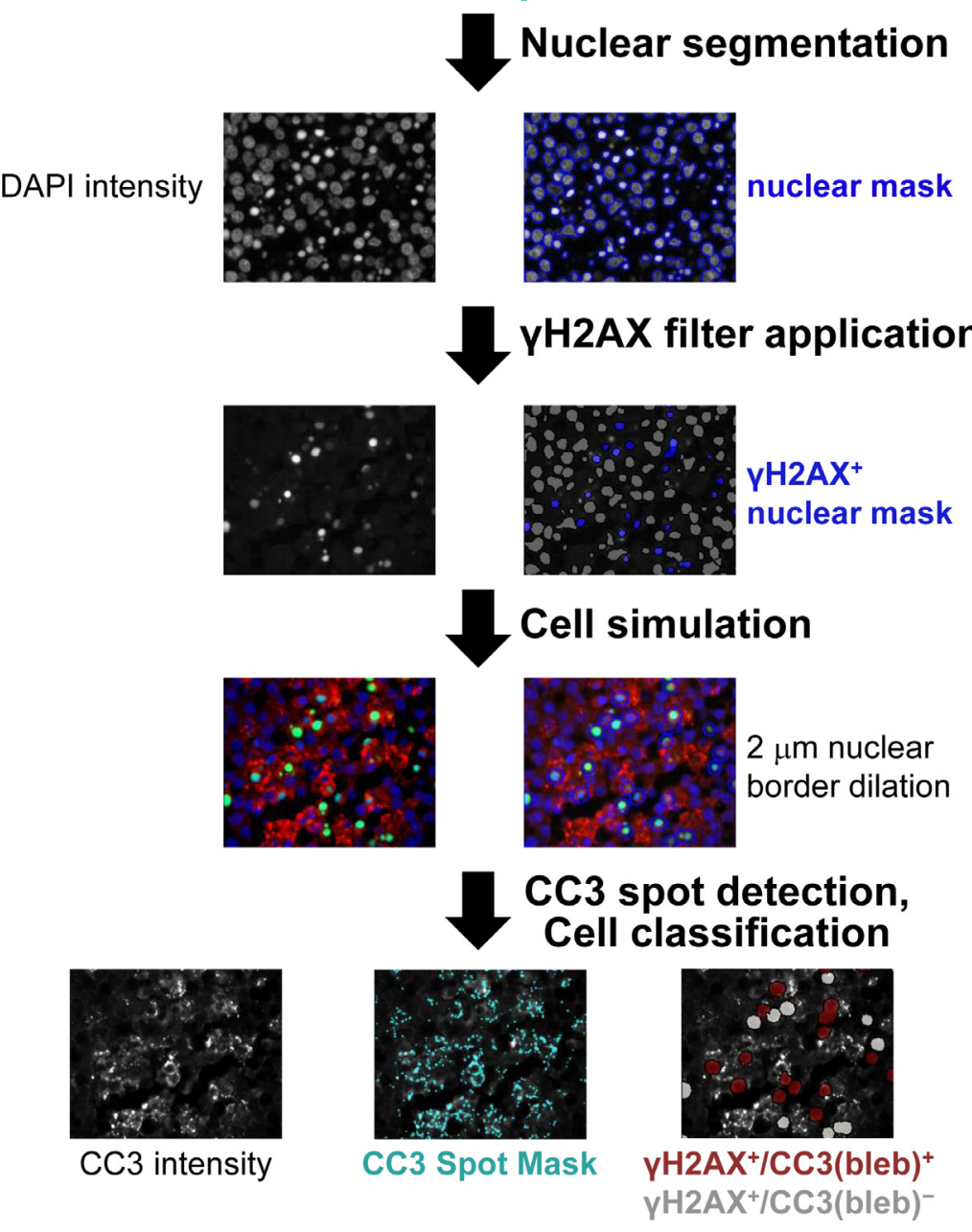

Figure 3: Workflow for quantitation of $\gamma \mathrm{H}_{2} \mathrm{AX}^{+} / \mathrm{CC} 3(\mathbf{b l e b})^{+}$cells in FFPE canine tumor tissue. Tissue stained with DAPI and anti-CC3 and anti- $\gamma \mathrm{H} 2 \mathrm{AX}$ antibodies was subjected to nuclear segmentation based on the DAPI signal. $\gamma \mathrm{H} 2 \mathrm{AX}^{+}$nuclei were defined based on nuclear $\gamma \mathrm{H} 2 \mathrm{AX}$ expression, and then cytoplasmic areas were simulated using a ring-based algorithm, with the cytoplasm defined through a set dilation from the nuclear border (1-5 $\mu \mathrm{m}$, established in an automated fashion on a specimen-by-specimen basis). CC 3 puncta in these $\gamma \mathrm{H} 2 \mathrm{AX}$-positive cells were defined using a spot algorithm for CC3 intensity, with a spot size range of $0.2-5 \mu \mathrm{m}^{2}$, and cells were classified as $\mathrm{CC} 3(\mathrm{bleb})^{+}$if they contained $\geq 2 \mathrm{CC} 3$ puncta per cell. Scale bar represents $50 \mu \mathrm{m}$. 
groups relative to vehicle is consistent with the observed efficacy differences for these groups and suggests that dose-dependent antitumor efficacy is associated with induction of both $\gamma \mathrm{H} 2 \mathrm{AX}$ and apoptosis, as would be expected for a DNA damaging agent. While the single time point examined may not represent peak $\gamma \mathrm{H}_{2} \mathrm{AX}^{+} /$ $\mathrm{CC} 3$ (bleb) $^{+}$coexpression, this assay displays the sensitivity to detect even low levels of marker coexpression.

We next examined $\gamma \mathrm{H} 2 \mathrm{AX}$ expression following treatment with the DNA crosslinking agent cisplatin in the A2780 ovarian carcinoma xenograft model over a 24hour time course. A single $6 \mathrm{mg} / \mathrm{kg}$ dose of cisplatin was previously shown to slow, but not inhibit, tumor growth in this model. Our analysis of tumor quadrants harvested from A2780 models treated with this dose revealed significant increases in the percentage of $\gamma \mathrm{H} 2 \mathrm{AX}^{+}$cells at 4,7 , and $24 \mathrm{~h}$ post-cisplatin administration, but no significant changes in the percentage of CC3(bleb) ${ }^{+}$or $\gamma \mathrm{H}_{2} \mathrm{AX}^{+} / \mathrm{CC} 3(\mathrm{bleb})^{+}$cells at any time point up to 24 hours (Figure 5). Similar to the pattern of $\gamma \mathrm{H} 2 \mathrm{AX}$ expression in the topotecan-treated xenografts, the $\gamma \mathrm{H} 2 \mathrm{AX}$ signal observed following cisplatin treatment was pan-nuclear rather than focal, indicating that the spatial pattern of $\gamma \mathrm{H} 2 \mathrm{AX}$ expression does not necessarily offer any additional information to distinguish between persistent DNA damage and apoptosis induced by genotoxic agents.
The induction of only $\gamma \mathrm{H} 2 \mathrm{AX}$ following a single $6 \mathrm{mg} /$ $\mathrm{kg}$ dose of cisplatin is consistent with the modest tumor growth delay observed following this treatment [23] and suggests that this dose causes steady accumulation of DNA DSBs that do not trigger apoptosis even at 24 hours.

\section{Colocalization of $\gamma \mathrm{H} 2 \mathrm{AX}$ and $\mathrm{CC} 3$ blebbing is a biomarker for the antitumor activity of the pro- apoptotic agent birinapant}

Birinapant is a mimetic of the proapoptotic protein Smac (second mitochondrial activator of caspases), which deactivates inhibitors of apoptosis (IAP) such as survivin, XIAP (X-chromosome-linked IAP) and cIAP1/2 (cellular IAP1/2) [6, 24-27]. Results from previous experiments [7] showed that treatment with 4 or $12 \mathrm{mg} / \mathrm{kg}$ birinapant $($ Q3D $\times 3)$ slowed or inhibited the growth of MDAMB-231 breast carcinoma xenograft model tumors but had no effect on the growth of OVCAR-3 ovarian carcinoma xenograft model tumors (Figure 6A). Reflecting this differential efficacy, analysis of tumor quadrants harvested after administration of a single 4 or $12 \mathrm{mg} / \mathrm{kg}$ birinapant dose revealed a substantial increase in the percentage of $\gamma \mathrm{H} 2 \mathrm{AX}^{+} / \mathrm{CC} 3(\mathrm{bleb})^{+}$cells 6 hours after treatment in MDA-MB-231, but not OVCAR-3, xenografts; signal in the MDA-MB-231 tumors returned to baseline by 24
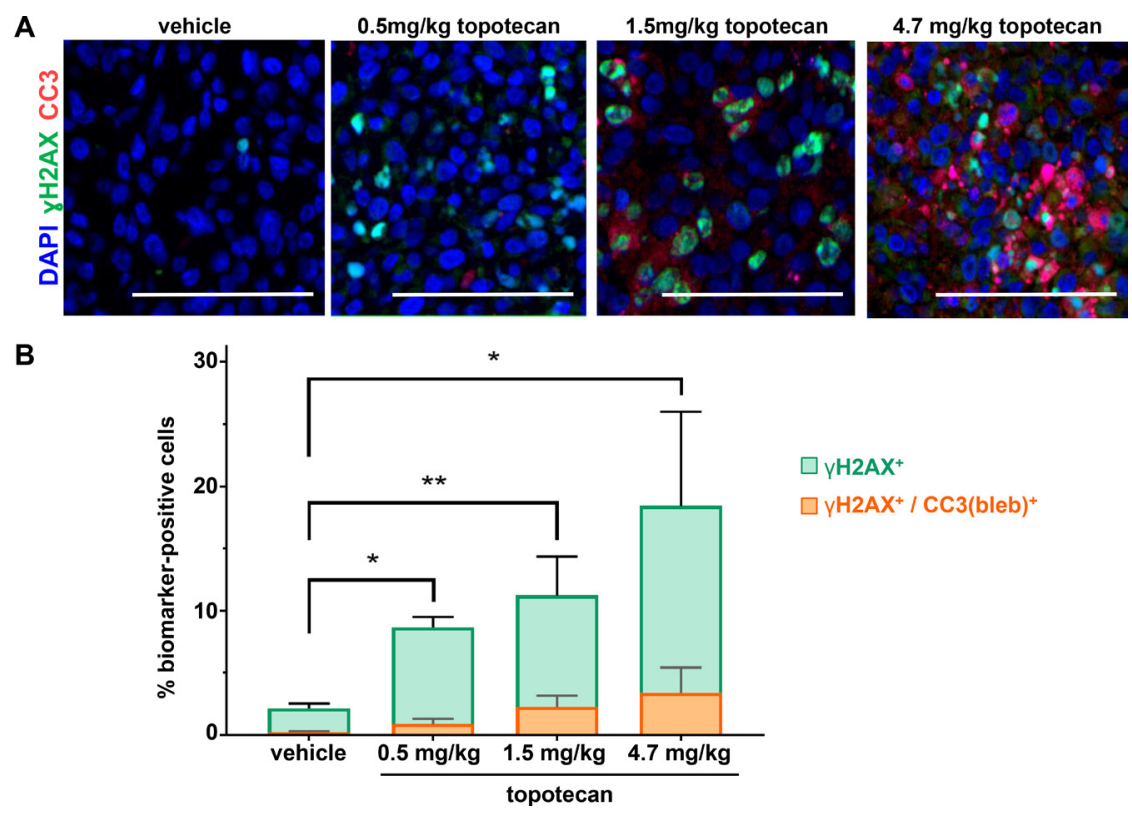

Figure 4: $\gamma \mathrm{H} 2 \mathrm{AX} / \mathrm{CC} 3(\mathrm{bleb})$ cellular colocalization assay results reveal dose-dependent induction of apoptosis at topotecan levels associated with tumor growth delay in the A375 melanoma xenograft model. Mice were administered the indicated doses of topotecan, and tumors were harvested for analysis at 4 hours post dose ( $n=4-6$ animals per treatment group). (A) Representative IFA images from tumor tissue stained with anti-CC3 (red), anti- $\gamma \mathrm{H} 2 \mathrm{AX}$ (green), and DAPI (blue) are shown for each treatment group; scale bar represents $100 \mu \mathrm{m}$. (B) Mean total percentages of topotecan-treated A375 xenograft tumor cells positive for $\gamma \mathrm{H} 2 \mathrm{AX}$ (green) or $\gamma \mathrm{H} 2 \mathrm{AX} / \mathrm{CC} 3$ blebbing cellular colocalization (orange) based on $\gamma \mathrm{H} 2 \mathrm{AX} / \mathrm{CC} 3$ (bleb) IFA quantitation of tumor sections from animals treated at the indicated doses (bars representing $\gamma \mathrm{H} 2 \mathrm{AX}$ and $\gamma \mathrm{H} 2 \mathrm{AX} / \mathrm{CC} 3$ [bleb] are overlaid for comparison). Mean values from 4-6 animals (and 8 image fields per animal) are shown for each group; error bars indicate standard deviation. Asterisks indicate statistically significant differences $\left({ }^{*} P<0.05,{ }^{* *} P<0.01\right)$; levels of significance were identical for comparisons of both $\gamma \mathrm{H} 2 \mathrm{AX}$ and $\gamma \mathrm{H} 2 \mathrm{AX} / \mathrm{CC} 3$ (bleb). 
hours at both dose levels (Figure 6B and 6C). Together, these results serve as proof-of-concept, demonstrating that the degree of $\gamma \mathrm{H} 2 \mathrm{AX}^{+} / \mathrm{CC} 3(\mathrm{bleb})^{+}$cell induction observed 6 hours after treatment with birinapant follows the degree of antitumor activity of this agent in the MDA-MB-231 and OVCAR-3 xenograft models.

\section{Induction of apoptosis by two novel indenoisoquinolines in canine clinical specimens}

Clinical feasibility of the $\gamma \mathrm{H} 2 \mathrm{AX} / \mathrm{CC} 3$ (bleb) assay was established by analyzing specimens from a clinical trial of the investigational indenoisoquinoline topoisomerase 1 inhibitors indotecan (LMP400) and indimitecan (LMP776) in canine lymphoma patients. Each of the specimens had been identified as positive for nuclear $\gamma \mathrm{H} 2 \mathrm{AX}$ during an initial analysis - a step that lends itself well to the workflow associated with large trials testing genotoxic agents as it allows the duplex staining and advanced image analysis to be applied only to the subset of patient samples for which additional mechanistic data can be obtained. Two patients with tumors exhibiting clear evidence of apoptosis, as detected by the $\gamma \mathrm{H} 2 \mathrm{AX} /$ $\mathrm{CC} 3$ (bleb) assay, are shown in Figure 7; these patient tumors exhibited maximum apoptotic responses of 5-9\% of cells positive for $\gamma \mathrm{H} 2 \mathrm{AX} / \mathrm{CC} 3$ (bleb) colocalization, reflecting the corresponding clinical responses of $>60 \%$ reductions in tumor volume. In contrast, seven canine patients that had $<22 \%$ reductions in tumor volume showed $<1.5 \% \gamma \mathrm{H} 2 \mathrm{AX}^{+} / \mathrm{CC} 3(\text { bleb })^{+}$cells at the 2 - and 6-hour time points (data not shown). Furthermore, at the time points of maximum total $\gamma \mathrm{H} 2 \mathrm{AX}$ response for the patient tumors shown in Figure 7, a substantial portion of the $\gamma \mathrm{H} 2 \mathrm{AX}^{+}$cells were apoptotic ( $82 \%$ and $38 \%$ for the patient tumors shown in Figure $7 \mathrm{~B}$ and $7 \mathrm{D}$, respectively), highlighting the role of this assay in deconvoluting the ambiguous $\gamma \mathrm{H} 2 \mathrm{AX}$ signal in clinical specimens. In all of our analyses of canine patient specimens, we performed high-content imaging and analysis for a minimum of 15,000 individual cells per biopsy specimen. Collectively, the data presented for the specimens in Figure 2 and Figure 7 demonstrate that this quantity of cells is sufficient to detect significant increases in CC3 blebbing and $\gamma \mathrm{H} 2 \mathrm{AX} /$ CC3(bleb) colocalization.

These canine patient samples also illustrate the utility of this assay in enabling temporal dissection of the DNA damage repair and apoptotic responses. For the patient treated with LMP776 (Figure 7A and 7B),
A
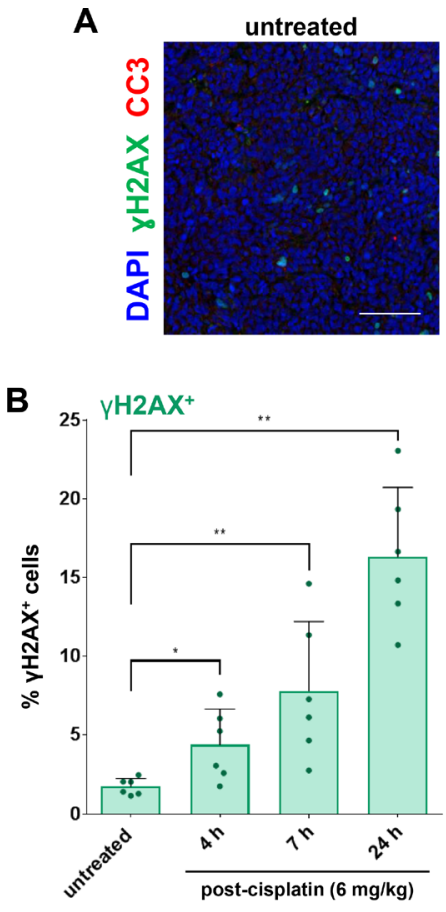

$4 \mathrm{~h}$ post-cisplatin
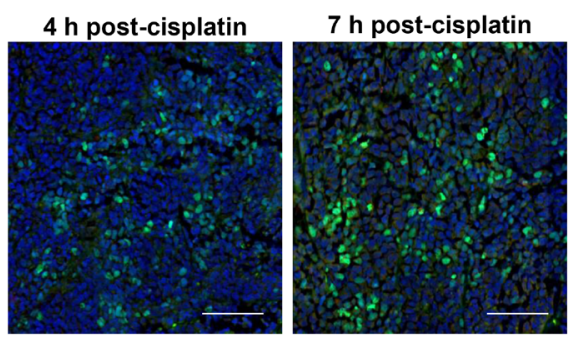

$24 \mathrm{~h}$ post-cisplatin

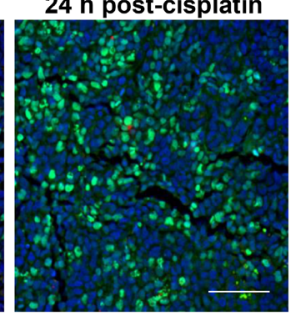

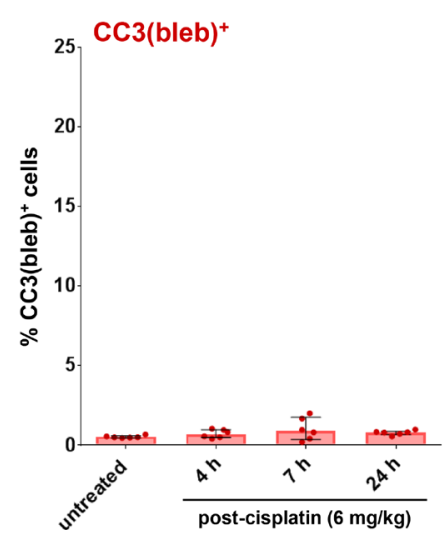

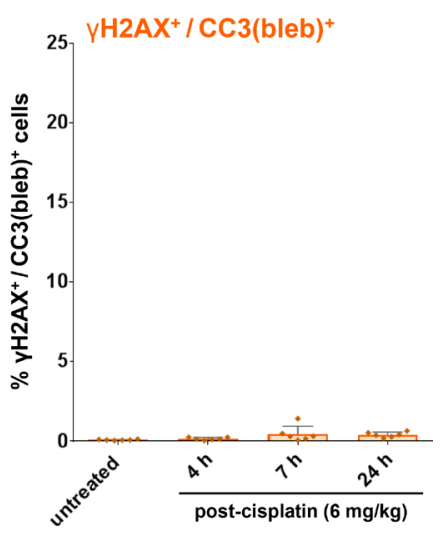

Figure 5: $\gamma \mathrm{H} 2 \mathrm{AX} / \mathrm{CC} 3($ bleb) cellular colocalization assay results reveal induction of DNA damage response, but not apoptosis, following treatment with a single dose of a cisplatin regimen associated with slowed tumor growth in the A2780 ovarian carcinoma xenograft model. Mice bearing A2780 xenografts were treated with a single dose of $6 \mathrm{mg} / \mathrm{kg}$ cisplatin, and tumors were harvested for $\gamma \mathrm{H} 2 \mathrm{AX} / \mathrm{CC} 3(\mathrm{bleb}) \mathrm{IFA}$ analysis at the indicated time points after cisplatin administration ( $n=6$ animals per time point). (A) Representative IFA images show cleaved caspase-3 (red), $\gamma \mathrm{H} 2 \mathrm{AX}$ (green), and DAPI (blue) staining in sections of FFPE tumor tissue; scale bars represent $100 \mu \mathrm{m}$. (B) Percentages of cisplatin-treated A2780 xenograft tumor cells positive for nuclear $\gamma \mathrm{H} 2 \mathrm{AX}$ (green, left), CC3 blebbing (red, center), and cellular colocalization of $\gamma \mathrm{H} 2 \mathrm{AX}$ and CC3 blebbing (orange, right), based on $\gamma \mathrm{H} 2 \mathrm{AX} /$ $\mathrm{CC} 3(\mathrm{bleb})$ IFA quantitation of tumor sections. Each data point represents the average of 6 image fields from each animal in each treatment group (error bars represent standard deviation). Asterisks indicate statistically significant differences for comparisons with the untreated control group $\left({ }^{*} P<0.05,{ }^{* *} P<0.01\right)$. 
the presence of $\gamma \mathrm{H} 2 \mathrm{AX}^{+}$cells but very few $\gamma \mathrm{H} 2 \mathrm{AX}^{+}$ $\mathrm{CC} 3$ (bleb) ${ }^{+}$cells at the 2-hour time point indicates a DNA damage repair response without appreciable apoptosis; in contrast, the significant increase in $\gamma \mathrm{H} 2 \mathrm{AX}$ positivity at the 6-hour time is due primarily to apoptotic cells (with $82 \%$ of $\gamma \mathrm{H} 2 \mathrm{AX}^{+}$cells also positive for CC3 blebbing). The temporal pattern of DNA damage repair response relative to apoptosis differed for the patient treated with LMP400 (Figure 7C and 7D). In this case, the peak $\gamma \mathrm{H} 2 \mathrm{AX}^{+}$-only and peak $\gamma \mathrm{H} 2 \mathrm{AX}^{+} / \mathrm{CC} 3(\mathrm{bleb})^{+}$responses both occurred at the 2-hour time point and then decreased at 6 hours, suggesting that the maximum apoptotic response may occur earlier for LMP776 compared to LMP400; however, whether these temporal differences in biomarker response are due to interpatient heterogeneity or differing drug pharmacokinetics and/or mechanisms of action remains to be determined upon completion of this clinical trial. Together, these data collected from core needle biopsies of naturally occurring lymphomas provide a fitness-for- purpose demonstration that indicates the assay is suitable for further use in pharmacodynamically driven clinical trials of DNA damaging or pro-apoptotic agents.

\section{DISCUSSION}

The ability to definitively interpret a positive $\gamma \mathrm{H} 2 \mathrm{AX}$ signal in tumor tissue improves our mechanistic understanding of investigational anticancer agents undergoing preclinical and clinical evaluation. Though there are numerous examples of $\gamma \mathrm{H} 2 \mathrm{AX}$ positivity in preclinical and clinical specimens, a positive $\gamma \mathrm{H} 2 \mathrm{AX}$ signal has been associated both with tumor volume reduction and tumor progression. Evaluating such specimens with the dual $\gamma \mathrm{H} 2 \mathrm{AX} / \mathrm{CC} 3$ (bleb) assay presented here allows us to interpret this ambiguous $\gamma \mathrm{H} 2 \mathrm{AX}$ positivity. Because scoring of $\gamma \mathrm{H} 2 \mathrm{AX}$-expressing cells on a microscopy platform is the preferred method for DSB detection, we developed a microscopy assay to enumerate cells
A

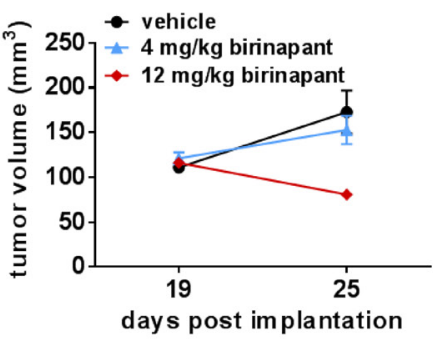

days post implantation

\section{C}

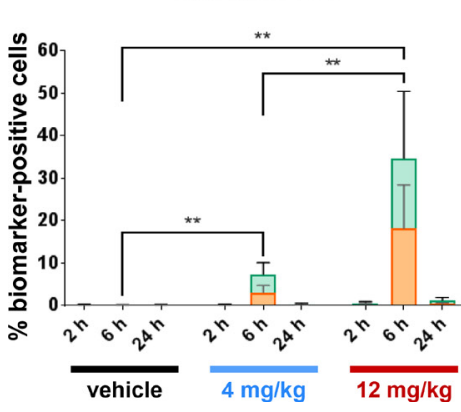

OVCAR-3

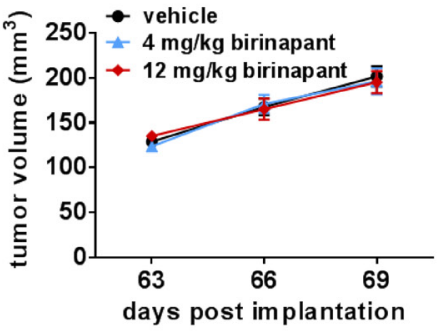

days post implantation

OVCAR-3

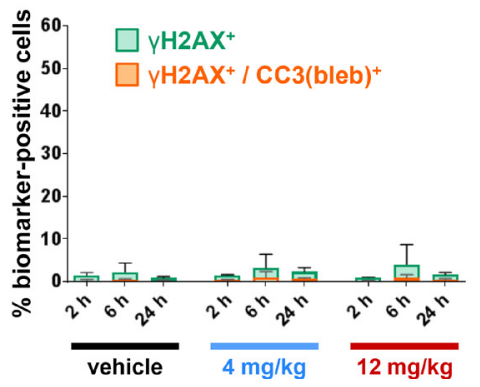

B
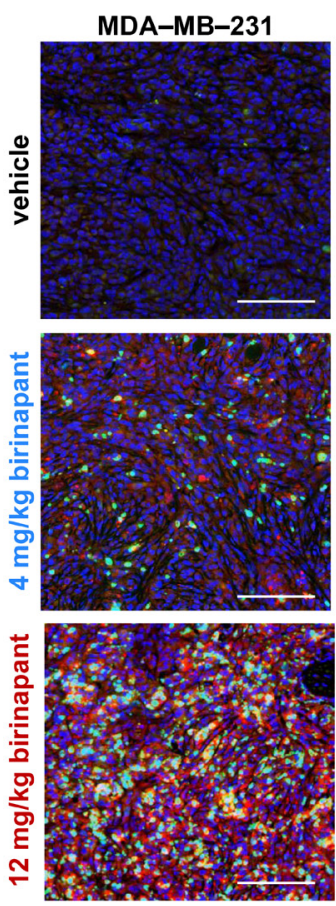

DAPI YH2AX CC3
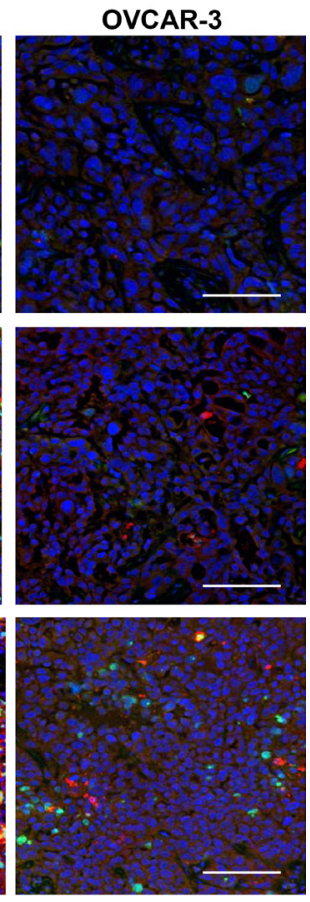

Figure 6: $\gamma \mathrm{H} 2 \mathrm{AX} / \mathrm{CC} 3(\mathrm{bleb})$ colocalization is a high-specificity biomarker for in vivo antitumor activity of the apoptosis-inducing agent birinapant. (A) Median tumor volumes ( \pm standard error of the median) on the indicated days are shown for MDA-MB-231 breast adenocarcinoma (left) and OVCAR-3 ovarian adenocarcinoma (right) xenograft models treated on post-implantation days 19, 22, and 25 (MDA-MB-231) or 63, 66, and 69 (OVCAR-3) with vehicle (black circles), $4 \mathrm{mg} / \mathrm{kg}$ birinapant (blue triangles), or $12 \mathrm{mg} / \mathrm{kg}$ birinapant (red diamonds); these data were published previously [6] ( $n=17-18$ animals per treatment group for each model). (B) and (C) MDA-MB-231 or OVCAR-3 xenograft models were treated with a single dose of vehicle or 4 or $12 \mathrm{mg} / \mathrm{kg}$ of birinapant, and tumors were harvested for $\gamma \mathrm{H} 2 \mathrm{AX} / \mathrm{CC} 3$ (bleb) IFA analysis at 2, 6, or 24 hours after birinapant administration $(n=6$ animals per treatment group per time point). (B) Representative IFA images are shown for sections of FFPE tumor tissue from MDA-MB-231 (left) or OVCAR-3 (right) xenograft tumors harvested at 6 hours post-dose and stained for cleaved caspase-3 (red), $\gamma \mathrm{H} 2 \mathrm{AX}$ (green), or with DAPI (blue); scale bars represent $100 \mu \mathrm{m}$. (C) Mean percentages of MDA-MB-231 (left) or OVCAR-3 (right) xenograft tumor cells positive for nuclear $\gamma \mathrm{H} 2 \mathrm{AX}$ (green) or cellular colocalization $\gamma \mathrm{H} 2 \mathrm{AX}$ and $\mathrm{CC} 3$ blebbing (orange) for each treatment group and time point based on quantitation of IFA images (bars representing $\gamma \mathrm{H} 2 \mathrm{AX}$ and $\gamma \mathrm{H} 2 \mathrm{AX} / \mathrm{CC} 3[\mathrm{bleb}]$ are overlaid for comparison). Bars indicate mean values from 6 animals (and 10 image fields per animal) in each treatment group; error bars represent standard deviation. Asterisks indicate statistically significant differences $\left({ }^{* *} P<0.01\right)$; levels of significance were identical for comparisons of both $\gamma \mathrm{H} 2 \mathrm{AX}$ and $\gamma \mathrm{H} 2 \mathrm{AX} / \mathrm{CC} 3(\mathrm{bleb})$. 
containing both $\gamma \mathrm{H} 2 \mathrm{AX}$ and blebbing-associated CC3 morphological structures in clinical specimens. By assessing the population of cells coexpressing both of these markers following efficacious therapies, we were able to evaluate the minimum proportion of apoptotic cells that is associated with efficacy at specific time points in these models. The $\gamma \mathrm{H} 2 \mathrm{AX}^{+} / \mathrm{CC} 3(\mathrm{bleb})^{+}$population in any given tumor sample is the result of a variety of factors, including the timing of induction for the two independent markers and the tumor cell kinetics of each drug; however, the $\gamma \mathrm{H} 2 \mathrm{AX} / \mathrm{CC} 3$ (bleb) assay is highly sensitive and allows for detection of even relatively low levels of apoptosis.

We report modulation of $\gamma \mathrm{H} 2 \mathrm{AX} / \mathrm{CC} 3$ (bleb) cellular colocalization and apoptosis in a manner associated with tumor volume reduction in all of the drug treatment settings examined. Treating the A375 xenograft model with topotecan increased apoptosis in a dose-dependent manner that was associated with tumor volume reduction (Figure 4 and [1]). On the other hand, treating A2780 xenograft-bearing mice with cisplatin induced significant
DNA damage, as indicated by $\gamma \mathrm{H} 2 \mathrm{AX}$-positive cells, without induction of apoptosis or tumor shrinkage [23]. Our xenograft studies with the cIAP inhibitor birinapant demonstrated extensive dose-dependent induction of apoptosis and antitumor efficacy in the sensitive MDAMB-231 xenograft tumor model but not in the drugresistant OVCAR-3 xenograft model. These preclinical birinapant data are consistent with those from a recent phase II clinical trial of birinapant in women with relapsed platinum-resistant or refractory epithelial ovarian cancer, in which qualitative assessment of two sets of paired biopsies revealed very few cells displaying colocalization of $\gamma \mathrm{H} 2 \mathrm{AX}$ and cytoplasmic $\mathrm{CC} 3$, consistent with the lack of efficacy of single-agent birinapant in this patient population [28]. Finally, clinical application of the $\gamma \mathrm{H} 2 \mathrm{AX} / \mathrm{CC} 3$ (bleb) assay to needle biopsy specimens collected from canine lymphoma patients treated with indenoisoquinolines revealed significant $\gamma \mathrm{H} 2 \mathrm{AX} / \mathrm{CC} 3$ (bleb) colocalization in post-treatment tumor specimens from two patients experiencing tumor
A

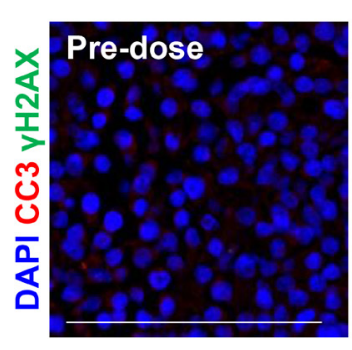

LMP776 patient
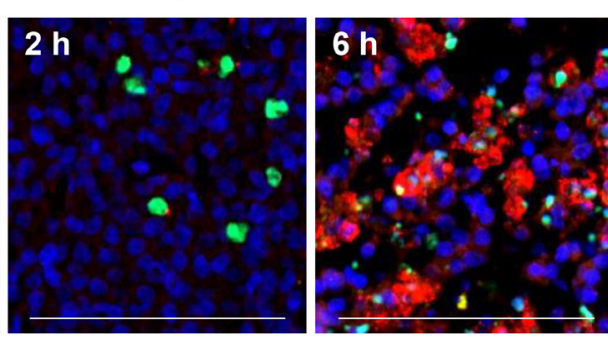

B

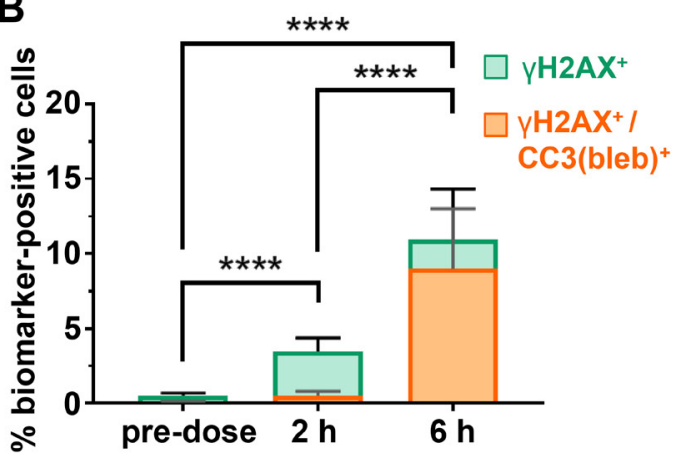

C

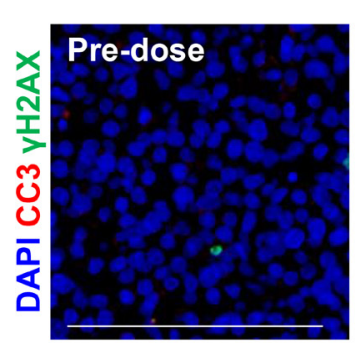

LMP400 patient

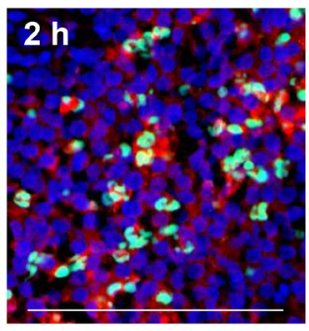

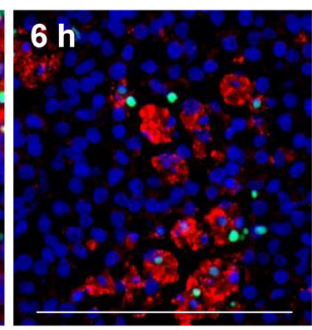

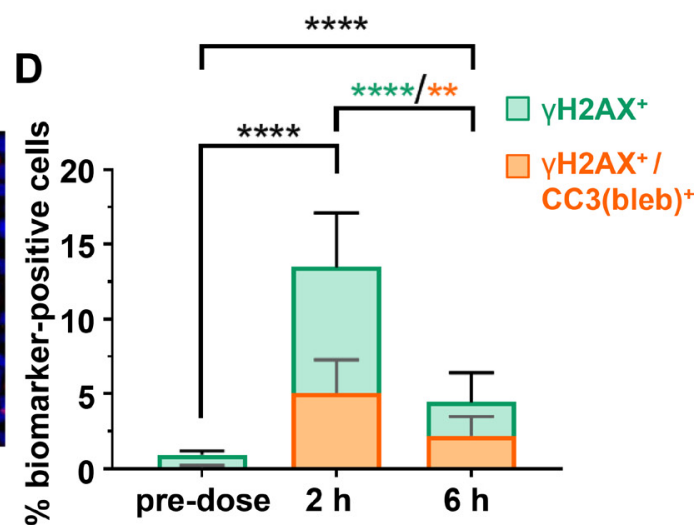

Figure 7: Analysis of the $\gamma \mathrm{H} 2 \mathrm{AX} / \mathrm{CC} 3(\mathrm{bleb})$ biomarker response to indenoisoquinoline treatment in core needle biopsies from canine lymphoma patients. Eighteen-gauge tumor needle biopsies were harvested from involved lymph nodes of 2 lymphoma patients. (A) and (C) Representative IFA images of sections from FFPE needle biopsies obtained at the indicated times on day 1 of QD $\times 5$ treatment with $17.5 \mathrm{mg} / \mathrm{m}^{2}$ LMP776 (A) or $65 \mathrm{mg} / \mathrm{m}^{2} \mathrm{LMP} 400$ (C); staining shows cleaved caspase-3 (red), $\gamma \mathrm{H} 2 \mathrm{AX}$ (green), and DAPI (blue), and scale bars represent $100 \mu \mathrm{m}$. (B) and (D) Quantitation of the $\gamma \mathrm{H} 2 \mathrm{AX}$ (green) and $\gamma \mathrm{H} 2 \mathrm{AX} / \mathrm{CC} 3(\mathrm{bleb})$ cellular colocalization (orange) signals corresponding to the images shown in (A) and (C), respectively. Bars indicate mean values from 13 image fields, and bars representing $\gamma \mathrm{H} 2 \mathrm{AX}$ and $\gamma \mathrm{H} 2 \mathrm{AX} / \mathrm{CC} 3$ (bleb) are overlaid for comparison; error bars represent standard deviation. Asterisks indicate statistically significant differences $\left({ }^{* *} \mathrm{P}<0.01,{ }^{* * * *} \mathrm{P}<0.0001\right)$ for comparisons of both $\gamma \mathrm{H} 2 \mathrm{AX}$ and $\gamma \mathrm{H} 2 \mathrm{AX} / \mathrm{CC} 3(\mathrm{bleb})(\mathrm{black})$ or $\gamma \mathrm{H} 2 \mathrm{AX}$ only (green) or $\gamma \mathrm{H} 2 \mathrm{AX} / \mathrm{CC} 3$ (bleb) (orange). The patient from which the data in (A) and (B) were obtained is Patient 3 from Figure $2 \mathrm{E}$; the patient featured in (C) and (D) is Patient 2 from Figure $2 \mathrm{C}$. 
shrinkage - and no such $\gamma \mathrm{H} 2 \mathrm{AX} / \mathrm{CC} 3$ (bleb) colocalization in tumors that were not responsive to these agents - further evidence that this assay is a reliable readout of cell death associated with tumor reduction.

We have developed a workflow to incorporate the $\gamma \mathrm{H} 2 \mathrm{AX} / \mathrm{CC} 3$ (bleb) assay into pharmacodynamic analyses of specimens from early-phase clinical trials involving DNA damage-inducing agents. The primary pharmacodynamic endpoint for genotoxic agents is induction of markers of DNA damage repair. Thus, rigorous analysis of multiple DNA damage repair markers (e.g., as detected by our $\gamma \mathrm{H} 2 \mathrm{AX}$, phospho-Nbs1, and Rad51 multiplex immunofluorescence assays) is an essential first step when analyzing specimens from studies of DNA damage-inducing agents. In an effort to preserve valuable patient tissue specimens for the most informative biomarker analyses, our current workflow for such trials prioritizes the primary pharmacodynamic endpoint by first performing multiplex assays of DNA damage repair markers - a process that often requires extensive analysis. Only if $\gamma \mathrm{H} 2 \mathrm{AX}$ induction is observed in a specimen is it assessed for apoptosis as a tertiary biomarker in order to decipher the meaning of the $\gamma \mathrm{H} 2 \mathrm{AX}$ signal; specimens for which no $\gamma \mathrm{H} 2 \mathrm{AX}$ is detected may be used instead for other exploratory biomarker analyses. However, for trials in which apoptosis is an appropriate primary pharmacodynamic endpoint (e.g., studies of birinapant), it may be preferable to begin with the $\gamma \mathrm{H} 2 \mathrm{AX} /$ $\mathrm{CC} 3$ (bleb) assay as a first step of specimen analysis. In such cases, extensive preclinical testing would be required to demonstrate that the agent of interest directly induces apoptosis rather than the apoptosis arising as a secondary event of widespread DNA damage.

While other microscopy-based methods of detecting apoptosis exist, such as TUNEL (terminal deoxynucleotidyl transferase dUTP nick-end labeling), these have limited quantitative capabilities due to insufficient signal-to-noise ratios - an issue that we have resolved via quantitation of $\mathrm{CC} 3$ blebbing, a marker of both the biochemical and morphological changes associated with apoptosis. Other quantitative, highspecificity assays for biomarkers of apoptosis exist in the multiplex immunoassay arena [6], but these are designed for Luminex-based measurements of tumor lysates rather than immunohistochemical or IFA analysis of intact tumor tissue. Thus, our method for identifying and enumerating gH2AX/CC3(bleb)-containing cells represents an important advance in the quantitative, microscopy-based analysis of apoptosis in tumor tissue. Our methodology can be applied as a highly specific apoptosis assay designed for IFA with fixed core needle biopsy specimens, and our results reveal important insights into mechanisms of action across multiple drug classes. This assay may have broad clinical and preclinical applicability to studies of investigational oncology agents and cytotoxic-based combination regimens.

\section{MATERIALS AND METHODS}

\section{BOND-MAX Autostainer staining protocol}

BOND-MAX staining methods have been previously described (21). The following antibody working solutions were prepared and loaded into the BOND-MAX Processing Module: a) $10 \mu \mathrm{g} / \mathrm{mL}$ rabbit monoclonal anti-cleaved caspase- 3 antibody (R\&D systems, MAB835, clone 269518, Milan, Italy) prepared in Bond Primary Antibody Diluent (Leica Biosystems, Buffalo Grove, IL), and goat-anti-rabbit Alexa Fluor 546 antibody (Invitrogen, Life Technologies, Grand Island, NY) prepared 1:100 in $1 \times$ Bond Wash Solution; b) $5 \mu \mathrm{g} /$ $\mathrm{mL}$ monoclonal anti-phospho (Ser 139) $\gamma \mathrm{H} 2 \mathrm{AX}-\mathrm{FITC}$ conjugate (Millipore, 16-202a, clone JBW301, Billerica, MA) antibody prepared in Bond Primary Antibody Diluent (Leica Biosystems, Buffalo Grove, IL); and c) 4',6-diamidino-2-phenylindole (DAPI) dihydrochloride, FluoroPure ${ }^{\mathrm{TM}}$ grade (Invitrogen, Life Technologies, Grand Island, NY) prepared at $0.25 \mu \mathrm{g} / \mathrm{mL}$ in Bond Primary Antibody Diluent.

\section{Image capture and quantitation}

Slides of xenograft and biopsy sections $(5 \mu \mathrm{m})$ stained with the cleaved caspase-3/ $\gamma \mathrm{H} 2 \mathrm{AX} / \mathrm{DAPI}$ multiplex mixture were scanned using the Aperio ScanScope FL image capture system (Leica Biosystems); at least six fields from each specimen slide were analyzed. Images were acquired using $20 \mathrm{X}$ magnification with a Leica Plan Apo 20X/0.7NA objective, $0.4622 \mu \mathrm{m}^{2} /$ pixel resolution, and images had a 16-bit depth. The $\mathrm{CC} 3$ exposure range was $0.8-3 \mathrm{~s}, \gamma \mathrm{H} 2 \mathrm{AX}$ exposure was $0.8-2 \mathrm{~s}$, and DAPI exposure was 20-30 ms. Images were extracted with a fixed size $(1,000 \times 1,000$ pixel $)$ from full tissue scans using Aperio ImageScope software. Images selected for extraction were derived from tumor tissue determined to be of sufficient quality as assessed via evaluation of an adjacent $\mathrm{H} \& \mathrm{E}$-stained section of each specimen by a board-certified pathologist [29]. Definiens Tissue Studio software (Definiens AG, Munich, Germany) was used for quantitative analysis of all xenograft and clinical biopsy material. Statistical significance was calculated by nonparametric Mann-Whitney tests. Proof of clinical readiness of the staining, image capture, and analysis was established with representative 18-gauge core needle biopsy specimens obtained from canine lymphoma patients.

\section{Cleaved caspase-3 intensity-based quantitation}

Nuclei were segmented based on DAPI intensity signal; nuclear size among the different studies ranged from $50-200 \mu \mathrm{m}^{2}$. Nuclei were filtered by area to remove regions of interest (ROIs) that were not properly segmented into single cell ROIs. The cytoplasmic mask 
was generated using a ring-based algorithm created using a set $(1-5 \mu \mathrm{m})$ dilation from the nuclear border. CC3 intensity within the cytoplasmic mask was quantitated by setting an intensity threshold and using a classification based on this threshold intensity to define a positive cell. The output for this measurement is percentage of cells positive for cytoplasmic CC3.

\section{Cleaved caspase-3 blebbing quantitation}

Nuclei were segmented and cytoplasmic masks generated as described above. CC3 puncta-a proxy for membrane blebbing (see Supplementary Figure 1) - were defined using a spot threshold algorithm for intensity and a spot size of $0.9 \mu \mathrm{m}^{2}$; spots with an area less than $0.2 \mu \mathrm{m}^{2}$ and greater than $5 \mu \mathrm{m}^{2}$ were filtered out. Cells with 2 or more puncta were classified as positive. The output is percentage of cells positive for CC3 blebbing. A workflow for enumeration of $\mathrm{CC} 3(\mathrm{bleb})^{+}$cells is provided in Figure 1.

\section{Quantitation of $\gamma \mathrm{H} 2 \mathrm{AX}$ and cleaved caspase-3 blebbing cellular colocalization}

Nuclei segmented as described above were filtered based on nuclear area and $\gamma \mathrm{H} 2 \mathrm{AX}$ intensity to remove ROIs that were not properly segmented into single cell ROIs and to select cells positive for $\gamma \mathrm{H} 2 \mathrm{AX}$ nuclear area signal using an automated custom intensity threshold [3]. Cytoplasmic masks were generated as described above. A spot algorithm was used to measure CC3 blebbing, as defined above, with cells containing 2 or more CC3 puncta per cell classified as positive. The output is percentage of cells positive for cellular colocalization of $\gamma \mathrm{H} 2 \mathrm{AX}$ and CC3 blebbing, where cells masked with red are defined as a positive and cells masked with white are negative. A workflow for enumeration of $\gamma \mathrm{H}_{2} \mathrm{AX}^{+} / \mathrm{CC} 3(\mathrm{bleb})^{+}$cells is provided in Figure 3.

\section{Drug-treated xenograft models}

Female athymic nu/nu mice were implanted with MDA-MB-231, A375, or A2780 human tumor cells as previously described $[1,6]$. OVCAR-3 tumor cells were implanted into female NOD SCID gamma (NSG) mice as previously described [6]. A375 xenograft quadrants were collected from mice 4 hours after intraperitoneal administration of vehicle (sterile water) or $0.5,1.5$, or $4.7 \mathrm{mg} / \mathrm{kg}$ topotecan (NSC 609699). The maximum tolerated dose of topotecan administered to mice once a day for 5 consecutive days (QD $\times 5$ ) is $4.7 \mathrm{mg} / \mathrm{kg}$ $\left(14.1 \mathrm{mg} / \mathrm{m}^{2}\right)$. A2780 xenografts were collected from mice following intraperitoneal administration of vehicle (saline) or $6 \mathrm{mg} / \mathrm{kg}$ cisplatin (NSC 119875) at 4, 7, or 24 hours after one dose. Dosing and sample collection for the birinapant studies are as described in [6]. All samples were fixed in neutral-buffered formalin and paraffin-embedded as previously described [1]. For the $\gamma \mathrm{H} 2 \mathrm{AX} / \mathrm{CC} 3$ (bleb) analyses of xenograft specimens, we analyzed $\geq 8,000$ individual cells per specimen, which was sufficient to detect significant increases in CC3 blebbing and $\gamma \mathrm{H} 2 \mathrm{AX} / \mathrm{CC} 3$ (bleb) colocalization. Frederick National Laboratory is accredited by AAALAC International and follows the Public Health Service Policy for the Care and Use of Laboratory Animals. Animal care was provided in accordance with the procedures outlined in the "Guide for Care and Use of Laboratory Animals" (National Research Council; 2011; National Academies Press; Washington, D.C.). All studies were conducted under an approved Animal Care and Use Committee protocol. Mice were housed in sterile, filter-capped, polycarbonate cages (Allentown Caging) in a barrier facility on a 12hour light/dark cycle, and provided with sterilized food and water, ad libitum. Prior to drug treatment, the animals were randomized into groups using a commercial software program (Study Director, Studylog Systems, Inc.).

\section{Canine clinical trial biopsy specimens}

Patient specimens consisting of FFPE 18-gauge core needle biopsies from a canine clinical trial that accrued outbred dogs with naturally-occurring lymphomas were used to establish clinical feasibility. Collection and handling conditions for canine lymphoma core needle biopsies were based on specimen preservation and processing SOPs used for analysis in core needle biopsies of human tumors (https://dctd.cancer.gov/ ResearchResources/ResearchResources-biomarkers.

htm). Dogs were treated with one of three investigational indenoisoquinoline topoisomerase I inhibitors: LMP400 (indotecan), LMP776 (indimitecan), or LMP744 [30]. Core biopsies were collected from involved lymph nodes prior to treatment and at 2 and 6 hours following administration of the first dose of a $\mathrm{QD} \times 5$ regimen. An additional lymph node sample was collected 24 hours after completion of the 5-day regimen. After collection, all specimens were immediately flash-frozen and then fixed in 10\% neutral buffered formalin (NBF) for 24 hours before paraffin-embedding (21). For the $\gamma \mathrm{H} 2 \mathrm{AX} /$ $\mathrm{CC} 3$ (bleb) analyses of canine patient biopsy specimens, we analyzed $\geq 15,000$ individual cells per specimen, which was sufficient to detect significant increases in CC3 blebbing and $\gamma \mathrm{H} 2 \mathrm{AX} / \mathrm{CC} 3$ (bleb) colocalization.

\section{Abbreviations}

CC3: cleaved caspase-3; CC3(bleb): membrane blebbing-associated cleaved caspase-3; cIAP1/2: cellular IAP1/2; DAPI: 4',6-diamidino-2-phenylindole; DSB: double strand break; FFPE: formalin-fixed, paraffinembedded; $\gamma \mathrm{H} 2 \mathrm{AX}$ : S139-phosphorylated histone H2AX; H \& E: hematoxylin and eosin; IAP: inhibitor of apoptosis; IFA: immunofluorescence assay; ROI: regions of interest; Smac: second mitochondrial activator of caspases; 
TUNEL: terminal deoxynucleotidyl transferase dUTP nick-end labeling; XIAP: X-chromosome-linked IAP.

\section{ACKNOWLEDGMENTS}

We thank Sandy Eldridge for pathology review and the Comparative Oncology Trials Consortium (COTC) institution veterinarians who enrolled patients and/or served on the Data and Safety Monitoring Board for the canine study of investigational indenoisoquinoline agents. We thank Brad Gouker and Donna Butcher for technical support of immunohistochemistry; Victor Lonsberry, Rachel Andrews and Dr. Kate Ferry-Galow for critical reagent supply of antibodies and specimen tracking; Michelle Ahalt-Gottholm and Suzie Borgel for technical support of in vivo experiments. We thank Drs. Andrea Regier Voth, Leidos Biomedical Research, Inc., and Sarah Miller, Kelly Government Services, for writing support in the preparation of this manuscript.

\section{CONFLICTS OF INTEREST}

The authors declare no potential conflicts of interest.

\section{FUNDING}

This project has been funded in whole or in part with federal funds from the National Cancer Institute, National Institutes of Health, under Contract No. HHSN261200800001E. The content of this publication does not necessarily reflect the views or policies of the Department of Health and Human Services, nor does mention of trade names, commercial products, or organizations imply endorsement by the U.S. Government. This research was supported [in part] by the Intramural Research Program of the NIH, National Cancer Institute, Center for Cancer Research.

\section{REFERENCES}

1. Kinders RJ, Hollingshead M, Lawrence S, Ji J, Tabb B, Bonner WM, Pommier Y, Rubinstein L, Evrard YA, Parchment RE, Tomaszewski J, Doroshow JH. Development of a validated immunofluorescence assay for $\gamma \mathrm{H} 2 \mathrm{AX}$ as a pharmacodynamic marker of topoisomerase I inhibitor activity. Clin Cancer Res. 2010; 16:5447-5457.

2. Do K, Wilsker D, Ji J, Zlott J, Freshwater T, Kinders RJ, Collins J, Chen AP, Doroshow JH, Kummar S. Phase I study of single-agent AZD1775 (MK-1775), a Wee1 kinase inhibitor, in patients with refractory solid tumors. J Clin Oncol. 2015; 33:3409-3415.

3. LoRusso PM, Li J, Burger A, Heilbrun LK, Sausville EA, Boerner SA, Smith D, Pilat MJ, Zhang J, Tolaney SM, Cleary JM, Chen AP, Rubinstein L, et al. Phase I safety, pharmacokinetic, and pharmacodynamic study of the
poly(ADP-ribose) polymerase (PARP) inhibitor veliparib (ABT-888) in combination with irinotecan in patients with advanced solid tumors. Clin Cancer Res. 2016; 22:3227-3237.

4. Lu C, Zhu F, Cho YY, Tang F, Zykova T, Ma WY, Bode AM, Dong Z. Cell apoptosis: requirement of H2AX in DNA ladder formation, but not for the activation of caspase-3. Mol Cell. 2006; 23:121-132.

5. Harada A, Matsuzaki K, Takeiri A, Mishima M. The predominant role of apoptosis in gammaH2 AX formation induced by aneugens is useful for distinguishing aneugens from clastogens. Mutat Res Genet Toxicol Environ Mutagen. 2014; 771:23-29.

6. Srivastava AK, Jaganathan S, Stephen L, Hollingshead MG, Layhee A, Damour E, Govindharajulu JP, Donohue J, Esposito D, Mapes JP, Kinders RJ, Takebe N, Tomaszewski JE, et al. Effect of a smac mimetic (TL32711, birinapant) on the apoptotic program and apoptosis biomarkers examined with validated multiplex immunoassays fit for clinical use. Clin Cancer Res. 2016; 22:1000-1010.

7. Bressenot A, Marchal S, Bezdetnaya L, Garrier J, Guillemin F, Plenat F. Assessment of apoptosis by immunohistochemistry to active caspase-3, active caspase-7, or cleaved PARP in monolayer cells and spheroid and subcutaneous xenografts of human carcinoma. J Histochem Cytochem. 2009; 57:289-300.

8. Duan WR, Garner DS, Williams SD, FunckesShippy CL, Spath IS, Blomme EA. Comparison of immunohistochemistry for activated caspase- 3 and cleaved cytokeratin 18 with the TUNEL method for quantification of apoptosis in histological sections of PC-3 subcutaneous xenografts. J Pathol. 2003; 199:221-228.

9. Jakob S, Corazza N, Diamantis E, Kappeler A, Brunner T. Detection of apoptosis in vivo using antibodies against caspase-induced neo-epitopes. Methods. 2008; 44:255-261.

10. Fujita J, Crane AM, Souza MK, Dejosez M, Kyba M, Flavell RA, Thomson JA, Zwaka TP. Caspase activity mediates the differentiation of embryonic stem cells. Cell Stem Cell. 2008; 2:595-601.

11. Oomman S, Strahlendorf H, Dertien J, Strahlendorf J. Bergmann glia utilize active caspase-3 for differentiation. Brain Res. 2006; 1078:19-34.

12. Fernando P, Brunette S, Megeney LA. Neural stem cell differentiation is dependent upon endogenous caspase 3 activity. FASEB J. 2005; 19:1671-1673.

13. Miura M, Chen XD, Allen MR, Bi Y, Gronthos S, Seo BM, Lakhani S, Flavell RA, Feng XH, Robey PG, Young M, Shi $\mathrm{S}$. A crucial role of caspase-3 in osteogenic differentiation of bone marrow stromal stem cells. J Clin Invest. 2004; 114:1704-1713.

14. Fernando P, Kelly JF, Balazsi K, Slack RS, Megeney LA. Caspase 3 activity is required for skeletal muscle differentiation. Proc Natl Acad Sci U S A. 2002; 99:11025-11030. 
15. Sordet O, Rebe C, Plenchette S, Zermati Y, Hermine O, Vainchenker W, Garrido C, Solary E, Dubrez-Daloz L. Specific involvement of caspases in the differentiation of monocytes into macrophages. Blood. 2002; 100:4446-4453.

16. Ishizaki Y, Jacobson MD, Raff MC. A role for caspases in lens fiber differentiation. J Cell Biol. 1998; 140:153-158.

17. MacFarlane M, Merrison W, Dinsdale D, Cohen GM. Active caspases and cleaved cytokeratins are sequestered into cytoplasmic inclusions in TRAIL-induced apoptosis. J Cell Biol. 2000; 148:1239-1254.

18. Weerasinghe SV, Ku NO, Altshuler PJ, Kwan R, Omary MB. Mutation of caspase-digestion sites in keratin 18 interferes with filament reorganization, and predisposes to hepatocyte necrosis and loss of membrane integrity. J Cell Sci. 2014; 127:1464-1475.

19. $\mathrm{Ku} \mathrm{NO}$, Strnad $\mathrm{P}$, Bantel H, Omary MB. Keratins: Biomarkers and modulators of apoptotic and necrotic cell death in the liver. Hepatology. 2016; 64:966-976.

20. Ford CA, Petrova S, Pound JD, Voss JJ, Melville L, Paterson M, Farnworth SL, Gallimore AM, Cuff S, Wheadon H, Dobbin E, Ogden CA, Dumitriu IE, et al. Oncogenic properties of apoptotic tumor cells in aggressive B cell lymphoma. Curr Biol. 2015; 25:577-588.

21. Solier S, Pommier Y. The nuclear gamma-H2AX apoptotic ring: implications for cancers and autoimmune diseases. Cell Mol Life Sci. 2014; 71:2289-2297.

22. Collins JA, Schandi CA, Young KK, Vesely J, Willingham MC. Major DNA fragmentation is a late event in apoptosis. J Histochem Cytochem. 1997; 45:923-934.

23. Plumb JA, Strathdee G, Sludden J, Kaye SB, Brown R. Reversal of drug resistance in human tumor xenografts by 2'-deoxy-5-azacytidine-induced demethylation of the hMLH1 gene promoter. Cancer Res. 2000; 60:6039-6044.

24. Condon SM, Mitsuuchi Y, Deng Y, Laporte MG, Rippin SR, Haimowitz T, Alexander MD, Kumar PT, Hendi MS, Lee YH, Benetatos CA, Yu G, Kapoor GS, et al. Birinapant, a smac-mimetic with improved tolerability for the treatment of solid tumors and hematological malignancies. J Med Chem. 2014; 57:3666-3677.
25. Benetatos CA, Mitsuuchi Y, Burns JM, Neiman EM, Condon SM, Yu G, Seipel ME, Kapoor GS, Laporte MG, Rippin SR, Deng Y, Hendi MS, Tirunahari PK, et al. Birinapant (TL32711), a bivalent SMAC mimetic, targets TRAF2-associated cIAPs, abrogates TNF-induced NF-kappaB activation, and is active in patient-derived xenograft models. Mol Cancer Ther. 2014; 13:867-879.

26. Allensworth JL, Sauer SJ, Lyerly HK, Morse MA, Devi GR. Smac mimetic Birinapant induces apoptosis and enhances TRAIL potency in inflammatory breast cancer cells in an IAP-dependent and TNF-alpha-independent mechanism. Breast Cancer Res Treat. 2013; 137:359-371.

27. Krepler C, Chunduru SK, Halloran MB, He X, Xiao M, Vultur A, Villanueva J, Mitsuuchi Y, Neiman EM, Benetatos C, Nathanson KL, Amaravadi RK, Pehamberger H, et al. The novel SMAC mimetic birinapant exhibits potent activity against human melanoma cells. Clin Cancer Res. 2013; 19:1784-1794.

28. Noonan AM, Bunch KP, Chen JQ, Herrmann MA, Lee JM, Kohn EC, O’Sullivan CC, Jordan E, Houston N, Takebe N, Kinders RJ, Cao L, Peer CJ, et al. Pharmacodynamic markers and clinical results from the phase II study of the SMAC-mimetic birinapant in women with relapsed platinum-resistant or refractory epithelial ovarian cancer. Cancer. 2016; 122:588-597.

29. Kinders R, Ferry-Galow K, Wang L, Srivastava AK, Ji J, Parchment RE. Implementation of validated pharmacodynamic assays in multiple laboratories: challenges, successes, and limitations. Clin Cancer Res. 2014; 20:2578-2586.

30. Beck DE, Agama K, Marchand C, Chergui A, Pommier Y, Cushman M. Synthesis and biological evaluation of new carbohydrate-substituted indenoisoquinoline topoisomerase I inhibitors and improved syntheses of the experimental anticancer agents indotecan (LMP400) and indimitecan (LMP776). J Med Chem. 2014; 57:1495-1512. 